\title{
Gender mix in twins and fetal growth, length of gestation and adult cancer risk
}

\author{
Barbara Luke ${ }^{a}$, Mary Hediger ${ }^{b}$, Sung-Joon Min ${ }^{c}$, Morton B. Brown ${ }^{d}$, Ruta B. Misiunas ${ }^{e}$, Victor Hugo Gonzalez-Quintero ${ }^{f}$, \\ Clark Nugent ${ }^{\mathrm{e}}$, Frank R. Witter ${ }^{\mathrm{g}}$, Roger B. Newman ${ }^{\mathrm{h}}$, Gary D. V. Hankins', David A. Grainger and George A. Macones ${ }^{\mathrm{k}}$ \\ ${ }^{a}$ Department of Epidemiology and Public Health, University of Miami School of Medicine, Miami, FL, ${ }^{b}$ Epidemiology Branch, Division of \\ Epidemiology, Statistics, and Prevention Research, National Institutes of Health, National Institute of Child Health and Human Development, \\ Department of Health and Human Services, Bethesda, MD, ' ${ }^{c}$ Division of Health Care Policy and Research, University of Colorado Health Sciences \\ Center, Denver, CO, ${ }^{d}$ Department Of Biostatistics, School of Public Health, University of Michigan, Ann Arbor, MI, ${ }^{e}$ Department of Obstetrics $\mathcal{E}$ \\ Gynecology, University of Michigan Medical School, Ann Arbor, MI, ${ }^{\prime}$ Department of Obstetrics \& Gynecology, University of Miami School of \\ Medicine, Miami, FL, ${ }^{8}$ Department of Gynecology \& Obstetrics, Johns Hopkins University School of Medicine, Baltimore, MD, ${ }^{h}$ Department of \\ Obstetrics \& Gynecology, Medical University of South Carolina, Charleston, SC, ${ }^{i}$ Department of Obstetrics E Gynecology, University of Texas \\ Medical Branch at Galveston, TX, ${ }^{j}$ Department of Obstetrics \& Gynecology, University of Kansas Medical School, Wichita, KS, and ${ }^{k}$ Department \\ of Obstetrics \& Gynecology, University of Pennsylvania School of Medicine, Philadelphia, PA, USA
}

Correspondence:

Barbara Luke, ScD, MPH, RD, Department of Epidemiology and Public Health, University of Miami School of Medicine, 1801 NW 9th Avenue, Room 200H, Miami, FL 33136, USA. E-mail:

bluke@med.miami.edu

\section{Summary}

This study evaluated the effect of gender mix (the gender combinations of twin pairs) on fetal growth and length of gestation, and reviewed the literature on the long-term effects of this altered fetal milieu on cancer risk. In singletons, it is well established that females weigh less than males at all gestations, averaging 125-135 g less at full term. This gender difference is generally believed to be the result of the effect of androgens on fetal growth. The gender difference in fetal growth is greater before the third trimester and less towards term, with males growing not only more, but also earlier than females. Plurality is a known risk factor for reduced fetal growth and birthweight. Compared with singletons, the mean birthweight percentiles of twins fall substantially (by $10 \%$ or more) below the singleton 10 th percentile by 28 weeks, below the singleton 50 th percentile by 30 weeks, and below the singleton 90 th percentile by 34 weeks. In unlike-gender twin pairs, it has been reported that the female prolongs gestation for her brother, resulting in a higher birthweight for the male twin than that of like-gender male twins. Other researchers have demonstrated that females in unlikegender pairs had higher birthweights than females in like-gender pairs.

Analyses from our consortium on 2491 twin pregnancies with known chorionicity showed longer gestations and faster rates of fetal growth in both males and females in unlike-gender pairs compared with like-gender male or female pairs, although these differences were not statistically significant. The post-natal effects for females growing in an androgenic-anabolic environment include increased sensation-seeking behaviour and aggression, lowered visual acuity, more masculine attitudes and masculinising effects of the auditory system and craniofacial growth. In contrast, there is no evidence to suggest that there might be a similar feminising effect on males from unlike-gender pairs. This hormonal exposure in utero may influence adult body size and susceptability to breast cancer.

\section{Introduction}

Twin pregnancies provide the unique opportunity to study the influence of an additional fetus on intrauterine growth and pregnancy outcome, as well as any long-lasting effects influencing adult health and dis- ease risk. In singletons, these associations between the fetal environment and adult health have been the topic of international debate and research interest as the fetal origins of adult disease. ${ }^{1-5}$ In this paper we will examine the intrauterine effects of gender mix (the gender 
combinations of twin pairs) on fetal growth and length of gestation, and present a review of the literature evaluating the long-term effects of this altered fetal milieu on cancer risk.

\section{Singletons}

It is well established that female infants weigh less than male ones at all gestational ages, yet are more likely to survive. ${ }^{6,7}$ Even among extremely low birthweight infants $(<1000 \mathrm{~g})$, female gender is associated with a better than threefold odds of survival (adjusted odds ratio [AOR] 3.06, 95\% confidence interval [CI] 1.71, 5.45). ${ }^{8}$ Among full-term singletons, white male infants average $135 \mathrm{~g}$ and black male infants average $125 \mathrm{~g}$ heavier than their respective female counterparts. ${ }^{9}$ The gender difference is generally believed to be the result of androgens on fetal growth. This is demonstrated in male newborns with hypospadias and reduced levels of androgens. ${ }^{10}$ Data from the Avon Longitudinal Study of Parents and Children showed that, after adjusting for gestation, males with hypospadias had significantly reduced overall growth compared with healthy males, averaging $226 \mathrm{~g}$ lighter in birthweight, $0.8 \mathrm{~cm}$ shorter in birth length, and $0.6 \mathrm{~cm}$ smaller in head circumference.

The action of androgens in males increases not only the rate of fetal weight gain, but may also alter its time course in utero. ${ }^{11,12}$ The gestational age at which children are born with a given weight varies by gender, with males born significantly and consistently younger than females; the age difference is most pronounced at lower birthweights. The gender difference in fetal growth is greater before the third trimester and less towards term, with males growing not only more, but also earlier than females. Pedersen ${ }^{13}$ reported significant first trimester gender differences in growth by ultrasound. Males averaged $2.0 \mathrm{~mm}$ longer crownrump length by $8-12$ weeks of gestation and $1.4 \mathrm{~mm}$ larger biparietal diameter by 16 weeks of gestation than females, resulting in $40 \mathrm{~g}$ heavier birthweight and $4 \mathrm{~mm}$ longer birth length. These gender differences in fetal size increased with advancing gestation, from approximately 1 day at 8-12 weeks of gestation to 67 days at term. It is speculated that some critical time windows of development may be slightly different between males and females, and that this phenomenon may be one of the reasons for gender differences in sensitivity to fetal programming. For example, reduced abdominal circumference at birth is positively associated with plasma concentrations of fibrinogen, ${ }^{14}$ serum cholesterol and serum apolipoprotein B in adult life, ${ }^{15}$ as well as death from coronary heart disease, ${ }_{r}^{16}$ all associations are stronger in men than in women, and are independent of length of gestation. It has been shown in animal models that the fetal pituitary gland regulates the onset of labour. In humans, this role has been supported by delayed onset of labour in fetal anencephaly. ${ }^{17}$ The fetal secretion of stress hormones is one factor precipitating labour. ${ }^{18}$ There appears to be a U-shaped relationship regarding male gender and length of gestation, with studies reporting an excess of males in preterm ${ }^{19-23}$ and post-term births. ${ }^{24}$

Several studies have reported significantly higher maternal serum human chorionic gonadotropin levels in uncomplicated pregnancies with a female vs. a male fetus. ${ }^{25-27}$ In pre-eclamptic vs. normotensive mothers, those pregnant with males had significantly higher levels of both human chorionic gonadotropin and testosterone serum levels, whereas in mothers pregnant with females only testosterone levels were elevated, ${ }^{28}$ indicating an androgen influence on the pathophysiological mechanism of pre-eclampsia.

\section{Twins}

Plurality is a known risk factor for reduced birthweight. Cogswell and Yip ${ }^{9}$ report that the difference in mean birthweight between full-term singleton and twin births is about $690 \mathrm{~g}$ among white infants and $630 \mathrm{~g}$ among black infants; the difference in mean birthweight between twin and triplet births is $>500 \mathrm{~g}$ for both white and black infants. Min et al.$^{29}$ have demonstrated that, although twins generally grow more slowly than singletons, the overall pattern of fetal growth for well-grown twins does not differ as much as from singletons as previously believed. Compared with singletons, ${ }^{30}$ the mean birthweight percentiles of twins fall substantially (by $10 \%$ or more) below the singleton 10th percentile by 28 weeks, below the singleton 50th percentile by 30 weeks and below the singleton 90 th percentile by 34 weeks. ${ }^{29}$ Glinianaia et al. ${ }^{31}$ also reported that twins and singletons have similar birthweight curves before 30 weeks, with progressive divergence with advancing gestation. Smith et al. ${ }^{32}$ reported that the fetal growth velocity for biparietal diameter, abdominal circumference and femur length in twins decreased with gestation advancing, with the downward trend more noticeable after 32 weeks; maximum and minimum growth occurred at 22-23 weeks 
and 36-37 weeks respectively, unrelated to birth order within the twin pair, fetal gender, chorionicity or zygosity.

\section{Gender mix}

Surprisingly few twin studies have considered the combined effect of both siblings in the pair on length of gestation and birthweight. ${ }^{22,23,33-37}$ Cooperstock et al..$^{23}$ reported a $9.2 \%$ excess of male fetuses in white twin births before 35 weeks of gestation, based on the matched file of Missouri twin births from 1978-90. James $^{38,39}$ suggests that males are born earlier than females because they are conceived earlier. He also suggests that, assuming equal availability of nutrients in dichorionic twin pregnancies, the males would be more successful in their competition for nutrients than their female siblings because females are programmed to grow more slowly, compared with males in likegender twin pregnancies. ${ }^{39}$ Loos et al. ${ }^{33,34}$ examined the effect of gender mix in dizygotic twin pregnancies from the East Flanders Prospective Twin Survey on birthweight and length of gestation. They reported that length of gestation in unlike-gender pairs was similar to that of female like-gender pairs, and significantly ( 0.4 weeks; $P=0.02$ ) longer than that of male like-gender pairs. Birthweight of girls from unlikegender pairs was similar to that of girls from likegender pairs, but boys from unlike-gender pairs weighed $78 \mathrm{~g}$ more than boys from like-gender pairs $(P=0.001)$. These researchers concluded that in unlikegender pairs it is the girl that prolongs gestation for her brother, resulting in a higher birthweight than that of like-gender boys.

Glinianaia et al..$^{35}$ evaluated the effect of gender mix on birthweight using the New Norwegian Twin Panel, which included all twin births from 1967-74 and still living in Norway in 1992. They showed that although they had comparable length of gestation, females in unlike-gender pairs had higher birthweights (by $37.6 \mathrm{~g}$ ) than females in like-gender pairs. Birth order within the twin pair also had a significant effect, with first-born females being $68 \mathrm{~g}$ heavier than second-born females in unlike-gender pairs, and $55 \mathrm{~g}$ heavier in like-gender pairs. Blumrosen et al. ${ }^{36}$ using data from the Israeli Birth Registry (which did not include gestational age), reported significantly higher birthweights of females, but not males, from like- vs. unlike-gender pairs. Orlebeke et al. ${ }^{37}$ reported that birthweight was not affected by the gender of the co-twin, although boys averaged $89 \mathrm{~g}$ heavier than girls and first-born twins averaged $61 \mathrm{~g}$ heavier than second-born twins.

Data from our consortium on 2491 twin pregnancies with known chorionicity are presented in Table 1. Among dichorionic twin pregnancies, unlike-gender pairs had a longer gestation by about 2.1 days $(P=0.08) \quad$ compared with like-gender boys and 1.4 days (NS) compared with like-gender girls. Boys in unlike-gender pairs were growing faster than boys in like-gender pairs $(+2.3 \mathrm{~g} /$ week between 20 and 28 weeks and $+1.8 \mathrm{~g} /$ week between 28 weeks and delivery, NS). Girls in unlike-gender pairs were growing faster in mid-gestation $(+4.6 \mathrm{~g} /$ week between 20 and 28 weeks, NS), but slower in late gestation $(-4.2 \mathrm{~g} /$ week from 28 weeks to delivery, NS). As a consequence, birthweight (adjusted for gestation) was only $20 \mathrm{~g}$ (NS) heavier for boys and $6 \mathrm{~g}$ (NS) heavier for girls in unlike-gender vs. like-gender pairs. These findings are in line with those of Glinianaia et al. ${ }^{35}$ of small increases in mean birthweights in unlike-gender twins compared with their like-gender counterparts. Also in agreement with the findings of Loos et al., ${ }^{33,34}$ we found the length of gestation to be 0.3 weeks longer for unlike-gender pairs than for like-gender boys, but in contrast, we found it also to be 0.2 weeks longer than like-gender girls, whereas Loos et al. reported 0.3 weeks shorter. This difference may in part be explained by our grouping by chorionicity and gender and by the ethnic diversity of our twins, whereas Loos et al. ${ }^{33,34}$ used zygosity and gender, and their sample was ethnically homogenous. In evaluating the effects of chorionicity in like-gender twin pairs, we found length of gestation to be longer in dichorionic vs. monochorionic pregnancies, averaging about 4.9 days for girls $(P=0.004)$ and 1.4 days for boys (NS), with heavier average birthweights (102 $\mathrm{g}$ in girls, NS, and $171 \mathrm{~g}$ in boys, $P=0.006$ ) (Table 1 ). Fetal growth rates were not significantly different among like-gender twins by chorionicity.

Twin pregnancies are at higher risk for pre-eclampsia compared with singletons, and male gender has been implicated as being a possible contributing factor. Basso and Olsen, ${ }^{40}$ in their analysis of the Danish National Birth Registry and Statistics Denmark's Fertility Database of births from 1980-96, reported an excess of males in pregnancies complicated by preeclampsia. Among twin pregnancies compared with singletons, the overall odds ratio (OR) for preeclampsia was 2.49 [95\% CI 2.25, 2.75]; by gender mix it was $2.23[1.89,2.68]$ for unlike-gender pregnancies, 
Table 1. Effect of gender mix and chorionicity on rates of fetal growth, length of gestation, and birthweight in twins ${ }^{\mathrm{a}}$

\begin{tabular}{|c|c|c|c|c|c|c|c|}
\hline & & \multicolumn{3}{|c|}{ Gender mix of twin pairs } & \multicolumn{3}{|c|}{$P$-value } \\
\hline & & G-G & G-B & B-B & G-G vs. G-B & G-G vs. B-B & G-B vs. B-B \\
\hline \multirow[t]{2}{*}{$(\mathrm{N}$, pairs $)$} & $\mathrm{Di}^{\mathrm{b}}$ & 481 & 959 & 551 & & & \\
\hline & Mono ${ }^{\mathrm{b}}$ & 250 & & 250 & & & \\
\hline \multirow[t]{2}{*}{ Length of gestation (weeks) } & $\mathrm{Di}$ & $35.9 \pm 0.1$ & $36.0 \pm 0.1$ & $35.7 \pm 0.1$ & 0.31 & 0.55 & 0.08 \\
\hline & Mono & $35.2 \pm 0.2$ & & $35.5 \pm 0.2$ & & 0.27 & \\
\hline Mono vs. Di $P$-value ${ }^{c}$ & & 0.004 & & 0.23 & & & \\
\hline \multicolumn{8}{|l|}{ Birthweight $(\mathrm{g})$} \\
\hline Females & $\mathrm{Di}$ & $2311 \pm 19$ & $2317 \pm 13$ & & 0.81 & & \\
\hline Males & $\mathrm{Di}$ & & $2430 \pm 13$ & $2410 \pm 18$ & & & 0.36 \\
\hline Average & $\mathrm{Di}$ & $2302 \pm 17$ & $2369 \pm 12$ & $2410 \pm 16$ & 0.001 & $<0.0001$ & 0.04 \\
\hline Average & Mono & $2200 \pm 23$ & & $2239 \pm 23$ & & 0.23 & \\
\hline Mono vs. Di $P$-value & & 0.65 & & 0.006 & & & \\
\hline \multicolumn{8}{|l|}{ Rates of fetal growth (g/week) } \\
\hline \multicolumn{8}{|l|}{ Early (0-20 weeks) } \\
\hline Female & $\mathrm{Di}$ & $16.8 \pm 0.6$ & $16.6 \pm 0.4$ & & 0.79 & & \\
\hline Male & $\mathrm{Di}$ & & $16.9 \pm 0.4$ & $17.4 \pm 0.5$ & & & 0.44 \\
\hline Average & $\mathrm{Di}$ & $16.7 \pm 0.5$ & $16.9 \pm 0.4$ & $17.4 \pm 0.5$ & 0.69 & 0.30 & 0.41 \\
\hline Average & Mono & $15.7 \pm 0.6$ & & $15.9 \pm 0.6$ & & 0.80 & \\
\hline Mono vs. Di $P$-value & & 0.12 & & 0.14 & & & \\
\hline \multicolumn{8}{|l|}{ Mid (20-28 weeks) } \\
\hline Female & $\mathrm{Di}$ & $81.3 \pm 3.1$ & $85.9 \pm 2.4$ & & 0.29 & & \\
\hline Male & $\mathrm{Di}$ & & $89.6 \pm 2.4$ & $87.3 \pm 3.1$ & & & 0.56 \\
\hline Average & $\mathrm{Di}$ & $81.5 \pm 3.1$ & $87.4 \pm 2.4$ & $87.3 \pm 3.0$ & 0.13 & 0.18 & 0.99 \\
\hline Average & Mono & $81.3 \pm 3.5$ & & $94.3 \pm 4.2$ & & 0.02 & \\
\hline Mono vs. Di $P$-value & & 0.30 & & 0.34 & & & \\
\hline \multicolumn{8}{|l|}{ Late (28 weeks-birth) } \\
\hline Female & $\mathrm{Di}$ & $141.1 \pm 3.4$ & $136.9 \pm 2.1$ & & 0.29 & & \\
\hline Male & $\mathrm{Di}$ & & $144.1 \pm 2.1$ & $142.3 \pm 2.8$ & & & 0.60 \\
\hline Average & $\mathrm{Di}$ & $141.2 \pm 3.0$ & $140.4 \pm 1.9$ & $142.1 \pm 2.5$ & 0.80 & 0.82 & 0.56 \\
\hline Average & Mono & $132.7 \pm 2.6$ & & $142.1 \pm 3.4$ & & 0.03 & \\
\hline Mono vs. Di $P$-value & & 0.36 & & 0.28 & & & \\
\hline
\end{tabular}

G-G, girl-girl; G-B, girl-boy; B-B, boy-boy.

${ }^{a}$ Least square means from models adjusting for mother's age, pregravid BMI, height, black ethnicity, primiparity, smoking, pre-eclampsia, gestational diabetes, fetal reduction; also adjusting for gestation for birthweight and rates of fetal growth models.

${ }^{b} \mathrm{Di}$ is dichorionic placentation; mono is monochorionic placentation.

'Within columns significance is between average of like-gender twins, comparing monochorionic vs. dichorionic.

$2.47[2.09,2.92]$ for female like-gender pregnancies, and $2.53[2.14,2.99]$ for male like-gender pregnancies. Luke et al. ${ }^{41}$ reported that fetal growth is reduced in twin pregnancies complicated by pre-eclampsia, an effect that precedes overt clinical symptoms in the mother. Average fetal growth of the twin pair is reduced by about $3.6 \mathrm{~g}$ /week between 20 and 28 weeks of gestation and by $5.7 \mathrm{~g} /$ week from 28 weeks to delivery.

\section{Postnatal effects among unlike-gender twins}

A growing body of literature suggests that females growing in an androgenic-anabolic fetal environment exhibit long-lasting effects. Findings consistent with possible hormonal influences in unlike-gender pairs include increased sensation-seeking behaviour and aggression, ${ }^{42,43}$ lowered visual acuity, ${ }^{44}$ more masculine attitudes ${ }^{45}$ masculinising effect on the female auditory system, ${ }^{46}$ and masculinising effect on the female craniofacial growth. ${ }^{47}$ There is no evidence to suggest that there might be a similar feminising effect on males from unlike-gender pairs; studies have reported no increased risk of breast cancer in the male of unlikegender twins. ${ }^{48}$ Glinianaia et al. ${ }^{35}$ suggests that the ability of androgens and oestrogens to transfer between fetuses may differ or that female tissues may have a 
greater sensitivity to a higher testosterone level in utero. Others ${ }^{45}$ have hypothesised that testosterone is the hormone most likely to both transfer between fetuses and to affect fetal development. Hormonal exposure in utero may influence adult female bodysize $^{49}$ and susceptibility to breast cancer. ${ }^{50}$

\section{Cancer in twins: effect of prenatal environment}

Oestrogens and other hormonal factors known to influence breast cancer risk in the adult may also play a critical role during the intrauterine period. ${ }^{51}$ Preeclampsia is associated with lowered levels of oestrogen and a decreased subsequent risk of breast cancer in the offspring ${ }^{52-54}$ while early preterm birth, neonatal jaundice, and dizygotic twinning are associated with elevated levels and higher breast cancer risks. Early preterm birth is associated with elevated maternal and fetal levels of oestrogen. ${ }^{55,56}$ The subsequent risk for breast cancer for women born $<33$ weeks of gestation has been shown to be elevated (OR 3.96 [95\% CI 1.45, 10.81]). ${ }^{53}$ Pregnancy steroid hormone levels have been shown to be risk factors for breast cancer. ${ }^{57}$ In contrast, the association between birthweight and breast cancer risk is not entirely consistent. ${ }^{54,58,59}$ Twin pregnancies are associated with higher levels of oestrogen than singleton pregnancies, a difference that is even more pronounced in dizygotic vs. monozygotic twin pregnancies. ${ }^{60-62}$ Human chorionic gonadotropin in both maternal and cord blood is higher in girl-girl twins and girl-boy twins than in boy-boy twins at delivery. ${ }^{25}$

Most $^{48,50,53,63,64}$ but not all ${ }^{60}$ studies of cancer risk among dizygotic twins show an increased risk of breast cancer. Among female twins with male co-twins, high birthweight constitutes a strong independent risk factor for breast cancer. Kaijser et al..$^{50}$ reported an AOR of 2.3 [95\% CI 1.09, 4.8] for each kilogram increase in birthweight for women with male co-twins, increasing to 4.3 [95\% CI 1.24, 14.7] for breast cancers diagnosed before age 50 . Swerdlow et al. ${ }^{65}$ pooled data from four case-control studies of female twins diagnosed with breast cancer conducted in Denmark, England, Wales, Finland and Sweden. Compared with their twin sisters, the risk of breast cancer was increased for women who were thinner (OR 1.44, [95\% CI 1.08, 1.91]) or taller (OR 1.27, [95\% CI 0.95, 1.70]) at age 10; for women who developed breasts earlier (OR 1.53, [95\% CI 1.14, 2.06]), and for women with a smaller waist-to-hip ratio at age 20 (OR 1.79, [95\% CI 1.00, 3.21]). These researchers concluded that childhood growth before puberty may affect the risk of premenopausal breast cancer, at least in women without a family history of breast cancer, and that the distribution of body fat in young adulthood may also be related to breast cancer risk. Androgens interact with oestrogens through competitive binding to sex hormone-binding globulin, and female twins with male co-twins and high birthweights are exposured in utero to both androgens from their brothers and to high endogenous oestrogen levels. ${ }^{61,62,66}$

Verkasalo et al. ${ }^{67}$ using the nationwide record linkage of the Finnish Twin Cohort Study, the Finnish Cancer Registry and the Central Population Register, followed up 12941 like-gender twin pairs. They concluded that the overall cancer incidence among twins resembled that among the general population, and that monozygotic co-twins of affected twins were at $50 \%$ higher risk than dizygotic co-twins. They concluded that inherited genetic factors accounted for about $18 \%$ of the liability in inter-individual variation in the risk of overall cancer, while non-genetic factors shared by twins accounted for 7\% and unique environmental factors for $75 \%$. Hemminki and $\mathrm{Li}^{68}$ using the nationwide Swedish Family Cancer Database on 10.2 million individuals and 62574 twins, reported that the overall risk of cancer in like-gender or unlike-gender twins was at the level of risk for singletons. Testicular cancer was increased among like-gender twins and all twins to a standardised incidence ratio (SIR) of 1.43; the SIR of breast cancer was 1.01 and 1.04 in like-gender and unlike-gender twins respectively. Probandwise (within-pair) analysis showed increased risks for Hodgkin's disease in males and breast cancer and childhood acute lymphoid leukaemia among females.

\section{Conclusions}

Male gender is associated with a faster rate of fetal growth, shorter length of gestation and higher birthweight, resulting primarily from anabolic effect of androgens. In twins, the effect of an unlike-gender twin appears to prolong gestation for the male and increase birthweight for the female. Male fetuses are also associated with significantly higher maternal levels of human chorionic gonadotropin and testosterone levels, as well as an excess of pre-eclampsia, and both early preterm and post-term births. While many of these differences may be of little clinical significance at birth, they may have implications for future health. Although many of the studies cited are based on small sample sizes, and their reported results await confirmation from subse- 
quent larger studies, it appears that the altered hormonal environment in utero may have important longlasting effects on the female of a mixed gender twin pair, including higher risks for cancer in adult life.

\section{References}

1 Paneth N, Susser M. Early origin of coronary heart disease (the 'Barker Hypothesis'). British Medical Journal 1995; 310:411-412.

2 Barker DJP. The fetal origins of coronary heart disease. Acta Paediatrica Supplement 1997; 422:78-82.

3 Sayer AA, Cooper C, Barker DJP. Is lifespan determined in utero? Archives of Disease in Childhood 1997; 77:F161-F162.

4 Eriksson JG, Forsén T, Tuomilehto J, Winter PD, Osmond C, Barker DJP. Catch-up growth in childhood and death from coronary heart disease: longitudinal study. British Medical Journal 1999; 318:427-431.

5 Waterland RA, Garza C. Potential mechanisms of metabolic imprinting that lead to chronic disease. American Journal of Clinical Nutrition 1999; 69:179-197.

6 Chase HC. Infant mortality and weight at birth: 1960 United States birth cohort. American Journal of Public Health 1969; 59:1618-1628.

7 Williams RL, Creasy RK, Cunningham GC, Hawes WE, Norris FD, Tashiro M. Fetal growth and perinatal viability in California. Obstetrics and Gynecology 1982; 59:624-632.

8 Bottoms SF, Paul RH, Mercer BM, MacPherson CA, Caritis $\mathrm{SN}$, Moawad AH, et al. Obstetric determinants of neonatal survival: antenatal predictors of neonatal survival and morbidity in extremely low birth weight infants. American Journal of Obstetrics and Gynecology 1999; 180:665-669.

9 Cogswell ME, Yip R. The influence of fetal and maternal factors on the distribution of birthweight. Seminars in Perinatology 1995; 19:222-240.

10 Hughes IA, Northstone K, Golding J, the ALSPAC Study Team. Reduced birth weight in boys with hypospadias: an index of androgen dysfunction? Archives of Disease in Childhood. Fetal and Neonatal Edition 2002; 87:F150-F151.

11 de Zegher F, Devlieger H, Eeckels R. Fetal growth: boys before girls. Hormone Research 1999; 51:258-259.

12 de Zegher F, Francois I, Boehmer ALM, Saggese G, Muller J, Hiort $\mathrm{O}$, et al. Androgens and fetal growth. Hormone Research 1998; 50:243-244.

13 Pedersen JF. Ultrasound evidence of sexual difference in fetal size in first trimester. British Medical Journal 1980; 281:1253.

14 Martyn CN, Meade TW, Stirling Y, Barker DJP. Plasma concentrations of fibrinogen and factor VII in adult life and their relation to intra-uterine growth. British Journal of Haematology 1995; 89:142-146.

15 Barker DJP, Martyn CN, Osmond C, Hales CN, Fall CHD. Growth in utero and serum cholesterol concentrations in adult life. British Medical Journal 1993; 307:1524-1527.

16 Barker DJP, Martyn CN, Osmond C, Wield GA. Abnormal liver growth in utero and death from coronary heart disease. British Medical Journal 1995; 310:703-704.

17 Myers DA, Nathanielsz PW. Biologic basis of term and preterm labor. Clinics in Perinatology 1993; 20:9-28.
18 Challis J, Sloboda D, Matthews S, Holloway A, Alfaidy N, Howe D, et al. Fetal hypothalamic-pituitary adrenal (HPA) development and activation as a determinant of the timing of birth, and of postnatal disease. Endocrine Research 2000; 26:489-504.

19 Wen SW, Goldenberg RL, Cutter GR, Hoffman HJ, Cliver SP. Intrauterine growth retardation and preterm delivery: prenatal risk factors in an indigent population. American Journal of Obstetrics and Gynecology 1990; 162:213-218.

20 McGregor JA, Leff M, Orleans M, Baron A. Fetal gender differences in preterm birth: findings in a North American cohort. American Journal of Perinatology 1992; 9:43-48.

21 Harlow BL, Frigoletto FD, Cramer DW, Evans JK, LeFevre $\mathrm{ML}$, Bain RP, et al. Determinants of preterm delivery in lowrisk pregnancies: the RADIUS study group. Journal of Clinical Epidemiology 1996; 49:441-448.

22 Cooperstock M, Campbell J. Excess males in preterm birth: interactions with gestational age, race, and multiple birth. Obstetrics and Gynecology 1996; 88:189-193.

23 Cooperstock MS, Bakewell J, Herman A, Schramm WF. Effects of fetal sex and race on risk of very preterm birth in twins. American Journal of Obstetrics and Gynecology 1998; 179:762-765.

24 Divon MY, Ferber A, Nisell H, Westgren M. Male gender predisposes to prolongation of pregnancy. American Journal of Obstetrics and Gynecology 2002; 187:1081-1083.

25 Steier JA, Myking OL, Ulstein M. Human chorionic gonadotropin in cord blood and peripheral maternal blood in singleton and twin pregnancies at delivery. Acta Obstetricia et Gynecologica Scandinavica 1989; 68:689-692.

26 Steier JA, Myking OL, Bergsjø PB. Correlation between fetal sex and human chorionic gonadotropin in peripheral maternal blood and amniotic fluid in second and third trimester normal pregnancies. Acta Obstetricia et Gynecologica Scandinavica 1999; 78:363-371.

27 Danzer H, Braunstein GD, Rasor J, Forsythe AW. Maternal serum chorionic gonadotropin concentrations and fetal sex prediction. Fertility and Sterility 1984; 34:336-340.

28 Steier JA, Ulstein M, Myking OL. Human chorionic gonadotropin and testosterone in normal and preeclamptic pregnancies in relation to fetal sex. Obstetrics and Gynecology 2002; 100:552-556.

29 Min S-J, Luke B, Gillespie B, Min L, Newman RB, Mauldin $\mathrm{JG}$, et al. Birth weight references for twins. American Journal of Obstetrics and Gynecology 2000; 182:1250-1257.

30 Hadlock FP, Harrist RB, Martinez-Poyer J. In utero analysis of fetal growth: a sonographic weight standard. Radiology 1991; 181:129-133.

31 Glinianaia SV, Skjærven R, Magnus P. Birthweight percentiles by gestational age in multiple births. Acta Obstetricia et Gynecologica Scandinavica 2000; 79:450-458.

32 Smith APM, Ong S, Smith NCS, Campbell D. A prospective longitudinal study of growth velocity in twin pregnancy. Ultrasound in Obstetrics and Gynecology 2001; 18:485-487.

33 Loos RJF, Derom C, Eeckels R, Derom R, Vlietinck R. Length of gestation and birthweight in dizygotic twins. Lancet 2001; 358:560-561.

34 Loos RJF, Derom C, Eeckels R, Derom R, Vlietinck R. Gestation and birthweight in dizygotic twins. Lancet 2002; 359:171-172. 
35 Glinianaia SV, Magnus P, Harris JR, Tambs K. Is there a consequence for fetal growth of having an unlike-sexed cohabitant in utero? International Journal of Epidemiology 1998; 27:657-659.

36 Blumrosen E, Goldman RD, Blickstein I. Growth discordance and the effect of a male twin on birth weight of its female cotwin: a population-based study. Journal of Perinatal Medicine 2002; 30:510-513.

37 Orlebeke JF, van Baal CM, Boomsma DI, Neeleman D. Birth weight in opposite sex twins as compared to same sex dizygotic twins. European Journal of Obstetrics, Gynecology, and Reproductive Biology 1993; 50:95-98.

38 James WH. Why are boys more likely to be preterm than girls? Plus other related conundrums in human reproduction. Human Reproduction 2000; 15:2108-2111.

39 James WH. Gestation and birthweight in dizygotic twins. Lancet 2002; 359:171-172.

40 Basso O, Olsen J. Sex ratio and twinning in women with hyperemesis or pre-eclampsia. Epidemiology 2001; 12:747749 .

41 Luke B, Min S-J, Gillespie B, Avni M, Witter FR, Newman RB, et al. The importance of early weight gain in the intrauterine growth and birth weight of twins. American Journal of Obstetrics and Gynecology 1998; 179:1155-1161.

42 Resnick SM, Gottesman II, McGue M. Sensation seeking in opposite-sex twins: an effect of prenatal hormones? Behavior Genetics 1993; 23:323-329.

43 Vierikko E, Pulkkinen L, Kaprio J, Viken R, Rose RJ. Sex differences in genetic and environmental effects on aggression. Aggressive Behavior 2003; 29:55-68.

44 Miller EM. Reported myopia in opposite sex twins: a hormonal hypothesis. Optometry and Visual Sciences 1995; 72:34-36.

45 Miller EM, Martin N. Analysis of the effect of hormones on opposite-sex twin attitudes. Acta Geneticae Medicae et Gemellologiae 1995; 44:41-52.

$46 \mathrm{McFadden} \mathrm{D}$. A masculinizing effect on the auditory systems of human females having male co-twins. Proceedings of the National Academy of Sciences USA 1993; 90:11900-11904.

47 Boklage CE. Interactions between opposite-sex dizygotic fetuses and the assumptions of Weinberg difference method epidemiology. American Journal of Human Genetics 1985; 37:591-605.

48 Cerhan JR, Kushi LH, Olson JE, Rich SS, Zheng W, Folsom $\mathrm{AR}$, et al. Twinship and risk of postmenopausal breast cancer. Journal of the National Cancer Institute 2000; 92:261-265.

49 Pietiläinen KH, Kaprio J, Räsänen M, Winter T, Rissanen A, Rose RJ. Tracking of body size from birth to late adolescence: contributions of birth length, birth weight, duration of gestation, parent's size, and twinship. American Journal of Epidemiology 2001; 154:21-29.

50 Kaijser M, Lichtenstein P, Granath F, Erlandsson G, Cnattingius S, Ekbom A. In utero exposures and breast cancer: a study of opposite-sexed twins. Journal of the National Cancer Institute 2001; 93:60-62.

51 Trichopoulos D. Hypothesis: does breast cancer originate in utero? Lancet 1990; 335:939-940.

52 Sanderson M, Williams MA, Daling JR, Holt VL, Malone KE, Self SG, et al. Maternal factors and breast cancer risk among young women. Paediatric and Perinatal Epidemiology 1998; 12:397-407.

53 Ekbom A, Hsieh CC, Lipworth L, Adami HO, Trichopoulos D. Intrauterine environment and breast cancer risk in women: a population-based study. Journal of the National Cancer Institute 1997; 89:71-76.

54 Ekbom A, Trichopoulos D, Adami HO, Hsieh CC, Lan SJ. Evidence of prenatal influences on breast cancer risk. Lancet 1992; 340:1015-1018.

55 Sedin G, Bergquist C, Lindgren PG. Ovarian hyperstimulation in preterm infants. Pediatric Research 1985; 19:548-552.

56 Mazor M, Hershkovitz R, Chaim W, Levy J, Sharony Y, Leiberman JR, et al. Human preterm birth is associated with systemic and local changes in progesterone/17ß-estradiol ratios. American Journal of Obstetrics and Gynecology 1994; 171:231-236.

57 Peck JD, Hulka BS, Poole C, Savitz DA, Baird D, Richardson $\mathrm{BE}$. Steroid hormone levels during pregnancy and incidence of maternal breast cancer. Cancer Epidemiology, Biomarkers and Prevention 2002; 11:361-368.

58 Michels KB, Trichopoulos D, Robins JM, Rosner BA, Manson JE, Hunter DJ, et al. Birthweight as a risk factor for breast cancer. Lancet 1996; 348:1542-1546.

59 Sanderson M, Williams MA, Malone KE, Stanford JL, Emanuel I, White E, et al. Perinatal factors and risk of breast cancer. Epidemiology 1996; 7:34-37.

60 Kappel B, Hansen K, Moller J, Faaborg-Anderson J. Human placental lactogen and dU-estrogen levels in normal twin pregnancies. Acta Geneticae Medicae et Gemellologiae 1985; 34:59-65.

61 Duff DB, Brown JB. Urinary oestriol excretion in twin pregnancies. Journal of Obstetrics and Gynaecology of the British Commonwealth 1974; 81:695-700.

62 TambyRaja RL, Ratnam SS. Plasma steroid changes in twin pregnancies. Progress in Clinical Biology and Research 1981; 69A:189-195.

63 Braun MM, Ahlbom A, Floderus B, Briton LA, Hoover RN. Effect of twinship on incidence of cancer of the testis, breast, and other sites (Sweden). Cancer Causes and Control 1995; 6:519-524.

64 Hsieh CC, Lan SJ, Ekbom A, Petridou E, Adami HO, Trichopoulos D. Twin membership and breast cancer risk. American Journal of Epidemiology 1992; 136:1321-1326.

65 Swerdlow AJ, De Stavola BL, Floderus B, Holm NV, Kaprio J, Verkasalo PK, et al. Risk factors for breast cancer at young ages in twins: an international population-based study. Journal of the National Cancer Institute 2002; 94:1238-1245.

66 Hardy MJ, Humeida AK, Bahijri SM, Basalamah AH. Late third trimester unconjugated serum oestriol levels in normal and hypertensive pregnancy: relation to birthweight. British Journal of Obstetrics and Gynaecology 1981; 88:976-982.

67 Verkasalo PK, Kaprio J, Koskenvuo M, Pukkala E. Genetic predisposition, environment and cancer incidence: a nationwide twin study in Finland, 1976-1995. International Journal of Cancer 1999; 83:743-749.

68 Hemminki K, Li X. Cancer risks in twins: results from the Swedish Family-Cancer Database. International Journal of Cancer 2002; 99:873-878. 